\title{
The Relationship between Time Based Management towards Manufacturing Capabilities: Investigating in Malaysian Manufacturing Industries
}

\author{
Mohammad Harith Bin Amlus ${ }^{1, *}$, Amlus Ibrahim $^{2}$, Ahmad Zaidi Abdullah $^{1}$, U. Naeimah Saraeh ${ }^{1}$, Adi Anuar Azmin ${ }^{1}$, Wan \\ Sallha Yusuf ${ }^{1}$ and Nur Afifah Shuib ${ }^{1}$ \\ ${ }^{1}$ Universiti Malaysia Perlis, Malaysia \\ ${ }^{2}$ Universiti Utara Malaysia, Malaysia
}

\begin{abstract}
Towards Industry 4.0, Malaysian Manufacturing Firms need to identify back their manufacturing capabilities especially to increase the performance and profit. This research is conducted to identify the role of manufacturing practices towards manufacturing capabilities. From this information it can provide valuable ingredients for companies in sustainable their operation. The identified factor of manufacturing practices is time based management and the dependent variables is manufacturing capabilities(focusing on agility. Through the survey, a total of 119 firms representing various industries in Northern Region of Malaysia had responded. The hypotheses involved were tested using correlation and regression techniques. The results of the study support the hypotheses. The multiple regression analysis indicates that there are significant relationships among this role on manufacturing capabilities. It is believed that results of this study will be beneficial to the top management of Malaysian manufacturing industries to focus on tim e based management and agility to increase the manufacturing capabilities.
\end{abstract}

\section{Introduction}

Manufacturing industries change dramatically and Malaysian government now set to move on the next stage after focus on agriculture industries and conventional manufacturing industries. Today, it has segued into yet another monumental era - the fourth industrial revolution, Industry 4.0, the name given to the latest evolution in the digitisation and automation of manufacturing processes. Industry 4.0 covers the entire value chain, including suppliers, procurement, design, logistics and even sales, resulting in higher productivity and flexibility. There is less wastage or storage, better monitoring and maintenance of machinery, and improved security and safety. The first industrial revolution started in the late 18th century with the shift from human or animal power to machines run by water or steam.

The second occurred between 1870 to 1914 with the introduction of electricity, and the rise of the steel and oil industries, triggering the era of mass production of goods and vehicles.

The third significant shift began in the 1960s with the entry of the first programmable logistic controllers and early versions of computers, boosting automation and control of production lines.

This spurred the extensive use of computer networks, and the eventual birth of the Internet changed the world in ways that no one could have imagined.

It is aimed at revolutionising the manufacturing industry, by switching from centralised to decentralised networks under which connected equipment and devices communicate with each other to analyse and respond to information received.

Manufacturing capabilities are grounded in the firm's people, skills, knowledge, processes, systems, and equipment. These capabilities can be assembled from different internal and external sources [17] and then deployed to create products and introduce them to the market in a timely manner. In this study, manufacturing capability involves four key elements that need to be addressed: the integration, acuity, control, and agility. Pursuing the idea that multiple capabilities are desirable, a few researchers have addressed the question of which capabilities a company should developed first [13]. Recently, researchers have related that manufacturing capability can be performed with good manufacturing practices, knowledge transfer and training [14]. With the combination of all this important factors, manufacturers would be able to develop their company capability to attain more profit and produce best product for customers.

\footnotetext{
* Corresponding author: harithamlus@gmail.com
} 


\subsection{Manufacturing Capabilities}

The concept of strategic capabilities that determine a manufacturing's contribution to the success of a firm is closely related to the notions of strategic resources, competences and priorities. In contrast to capabilities, resources are something a firm possesses or has access to, not what a firm is able to do. Resources can be tangible, e.g. specialized production systems, and intangible, e.g. level of training of workers [9]. Based on such resources, capabilities are developed. For instance, flexible production systems in combination with highly skilled workers or resources, allow to produce in a flexible way, capability. Capabilities allow an enterprise to develop and to exploit resources in order to generate profit through its products and services [1].

\subsection{Agility}

Agility is the ability to easily move from one manufacturing state to another. Agility divided to two criteria which are volume flexibility and mix flexibility. Volume flexibility refer to the ability of efficiently produce wide ranges in the demanded volumes of products. Mix flexibility is the ability to manufacture a variety of products, over a short time span, without modifying facilities [16]. The new concept agility in manufacturing, these drivers are competition, fragmentation of mass market, cooperative production relationship, evolving customer expectations, and increasing social pressures. The main issue in this new area of manufacturing management is the ability to cope with unexpected changes, to survive unprecedented threats of business environment, and to take advantage of changes as opportunities. This ability is called agility or agile manufacturing.

Agile manufacturing that was sometimes mixed up and confused with previous thought schools of manufacturing management such as flexibility and lean manufacturing has been backed for having novel concepts beyond the former remedies. This has happened thanks to the wide concern it received during the past few years, though in place this has been a natural result of the increasing need to resolve problems with the socalled remedies and increasing pressures on manufacturing companies in competing for success. Agility in concept comprises two main factors. They are responding to change (anticipated or unexpected) in proper ways and due time and exploiting changes and taking advantage of them as opportunities. These, indeed necessitate a basic ability that is sensing, perceiving and anticipating changes in the business environment of the company. An agile manufacturer, in this way is an organisation with a broad vision on the new order of the business world, and with a handful of capabilities and abilities to deal with turbulence and capture the advantageous side of the business.
Agility is an ability and a character that every manufacturing company must have to be able to survive and prosper in the new order of the world business environment. Different organisations are different in the way they should respond to changing business environment, so they need different levels of agility. Agility is a response to the changes that a company faces, and shall become a characteristic of the company. Therefore, the way that the company should act in turbulent circumstances of the business environment, which is called agility, is a direct function of changes in the business environment, and also the business environment itself and the company's situation. Agility in concept is a strategic response to the new criteria of the business world, and in practice, is a strategic utilization of business methods, manufacturing and management processes, practices and tools, most of which are already developed and used by industries for certain purposes, and some are under development to facilitate the capabilities that are required for being agile. Information system/technology in its utmost level of timeliness, coverage, communication ability, data banking and interchange, etc., is a major differentiator of an agile manufacturing company compared to traditional systems.

\subsection{Time Based Management}

The lead time is the time a customer must wait between order placement and receipt. Reliability or dependability (on-time delivery, OTD) reflects on the company's reliability in delivering a customer's order on or before the quoted delivery date. There is growing recognition of the importance of delivery reliability as a criterion in most markets. Its change toward being a qualifier is part of that competitive perspective. Delivery lead time or speed (Order Fulfilment lead time, OFLT) is about short delivery lead times and involves decisions in production stability, investments in capacity and/or inventory and the control of workflow. Another measure could be Time-to-Market for new products which manufacturing effects. Therefore, it is essential to consider these factors in studying manufacturing capabilities. This study focuses on manufacturing practices namely time based management The investigation on the effects of organizational capabilities on the manufacturing capabilities addressed by the following hypotheses;

$H_{l}$ Time Based Management has significant influence on Agility 


\section{Methodology}

\subsection{The Sample and Data}

A survey was conducted to collect cross sectional data in Northern Region of Malaysia which is one of the state introduce as the Silicon Valley of Malaysia. The population of this study was the Top Management and Managers. These grades consist of management and professional employees which identified a group with high potential to engage manufacturing capabilities. The selection of the survey location and the sample was due to the Federation of Manufacturers of Malaysia (FMM).

A set of questionnaire was formulated and designed based on the previous literature in the subject area. The questionnaires were emailed to 160 respondents. 119 sets questionnaires received within two weeks giving the response rate of $74.4 \%$. The sample profile of the survey is shown in Table 1.

Table 1. Sample profile of the respondent

\begin{tabular}{|c|c|c|c|}
\hline Variables & Item & Frequency & $\begin{array}{c}\text { Percentage } \\
(\%)\end{array}$ \\
\hline $\begin{array}{l}\text { Companies's } \\
\text { Type }\end{array}$ & $\begin{array}{l}\text { Malaysian } \\
\text { owned } \\
\text { Foreign } \\
\text { owned } \\
\text { Joint } \\
\text { Venture } \\
\end{array}$ & $\begin{array}{l}75 \\
28 \\
16\end{array}$ & $\begin{array}{l}63.0 \\
23.5 \\
13.5\end{array}$ \\
\hline $\begin{array}{l}\text { Size of } \\
\text { Company( In } \\
\text { term of Full } \\
\text { Time } \\
\text { Employees }\end{array}$ & $\begin{array}{l}\text { Less than } \\
5 \\
5 \text { to } 50 \\
51 \text { to } 150 \\
\text { More than } \\
150\end{array}$ & $\begin{array}{l}- \\
- \\
36 \\
83\end{array}$ & $\begin{array}{c}- \\
- \\
30.0 \\
69.7\end{array}$ \\
\hline $\begin{array}{l}\text { Respondents' } \\
\text { Job } \\
\text { Designation }\end{array}$ & $\begin{array}{l}\text { General } \\
\text { Manager } \\
\text { Manager } \\
\text { Executive }\end{array}$ & $\begin{array}{c}3 \\
89 \\
27\end{array}$ & $\begin{array}{c}2.5 \\
74.8 \\
22.7\end{array}$ \\
\hline $\begin{array}{l}\text { Year of } \\
\text { designation }\end{array}$ & $\begin{array}{l}\text { Less than } \\
1 \text { years } \\
1-5 \text { years } \\
6-10 \\
\text { years } \\
\text { More than } \\
10 \text { years }\end{array}$ & $\begin{array}{c}8 \\
31 \\
17 \\
63\end{array}$ & $\begin{array}{c}6.7 \\
26.1 \\
14.3 \\
52.9\end{array}$ \\
\hline $\begin{array}{l}\text { Education } \\
\text { level }\end{array}$ & $\begin{array}{l}\text { Degree } \\
\text { Master } \\
\text { Degree } \\
\text { PhD } \\
\end{array}$ & $\begin{array}{c}98 \\
20 \\
1\end{array}$ & $\begin{array}{c}82.3 \\
16.8 \\
0.9\end{array}$ \\
\hline
\end{tabular}

From Table 1 it is found that more than $63 \%$ respondents are Malaysian owned companies and 83 companies had more than 150 workers in their operation. The respondents are 3 General manager, 89 Manager and 27 Executive and 63 from the respondent work more than 10 years. 98 from this respondent are from Degree level.

\subsection{Reliability Analysis}

An internal consistency analysis was performed separately for the items of each managerial commitment and system perspectives by using the SPSS version 20, reliability procedure. Based on the suggestion by [8], the author highlighted an acceptable alpha value is greater than 0.6. As show in Table 2, the alpha values of reliability analysis for this study ranges from 0.70 to 0.85 . From the results obtained, all the alpha values are greater than 0.7. Thus it can be concluded that this instrument has good internal consistency and is therefore reliable.

Table 2: Reliability analysis result

\begin{tabular}{lcc}
\hline \multicolumn{2}{c}{ Variables } & Number of \\
\hline $\begin{array}{l}\text { Time Based } \\
\text { Management }\end{array}$ & 4 & Alpha \\
\hline Agility & & 0.812 \\
\hline
\end{tabular}

Descriptive analyses for the organizational capabilities and manufacturing capabilities are shown in Table 4 and Table 5. The levels of organizational capabilities and manufacturing capabilities are based on the levels of mean score range provided in Table 3.

Table 3: Level of Mean Score Range

\begin{tabular}{cc}
\hline $\begin{array}{c}\text { Range of mean } \\
\text { score }\end{array}$ & Level \\
\hline $1.00-2.33$ & Low \\
$2.34-3.67$ & Medium \\
$3.68-5.00$ & High \\
\hline
\end{tabular}

\section{Findings}

\subsection{The Level of Manufacturing Capabilities}

Manufacturing capabilities among the manufacturing companies are measured based on the values of means and standard deviations. Table 4 shows the ranking of knowledge transfer and the value of mean and standard deviation for each activity. 
Table 4: Mean Values of Manufacturing Capabilities

\begin{tabular}{ccc}
\hline Activities & Mean & $\begin{array}{c}\text { Standard } \\
\text { Deviation }\end{array}$ \\
\cline { 3 - 3 } $\begin{array}{c}\text { Able to efficiently produce } \\
\text { wide ranges in the } \\
\text { demanded volumes of } \\
\text { products }\end{array}$ & 3.64 & 0.687 \\
$\begin{array}{c}\text { Able to manufacture a } \\
\text { variety of products, over a } \\
\text { short time span, without } \\
\text { modifying facilities }\end{array}$ & 3.68 & 0.643 \\
$\begin{array}{c}\text { Able to accelerate or } \\
\text { decelerate the rate of } \\
\text { production quickly to } \\
\text { handle large fluctuations } \\
\text { in demand }\end{array}$ & & \\
\hline $\begin{array}{c}\text { Manufacturing } \\
\text { Capabilities }\end{array}$ & 3.66 & 0.634 \\
\hline
\end{tabular}

Mean values explained the propensity of the respondent to involve with manufacturing capabilities (Li, 2000). The mean values in range of 2.34 to 3.67 is categorized as medium stage.

The mean score for the overall manufacturing capabilities is 3.66. This indicated that the level of manufacturing capabilities among manufacturing companies is at the medium stage.

\subsection{The Level of Time Based Management}

Table 5 gives the mean values for the eight organizational capabilities. It is shown that one of the organizational capabilities has more than 3.67 mean values which is 3.72. Base on Table 5, the levels of these organizational capabilities are considered as medium stage among the manufacturing companies.

Table 5: Mean Values of Time Based Management

\begin{tabular}{lcc}
\hline \multicolumn{1}{c}{ Activities } & Mcan & $\begin{array}{c}\text { Standard } \\
\text { deviation }\end{array}$ \\
\hline $\begin{array}{l}\text { Indicate The } \\
\text { Importance Given To } \\
\text { Delivery Time }\end{array}$ & 3.61 & 0.861 \\
$\begin{array}{l}\text { Indicate The } \\
\text { Importance Given To } \\
\text { Engineering Time }\end{array}$ & 3.72 & 0.713 \\
$\begin{array}{l}\text { Indicate The } \\
\text { Importance Given To }\end{array}$ & 3.45 & 0.762 \\
Procurement & & \\
$\begin{array}{l}\text { Indicate The } \\
\text { Importance Given To } \\
\text { Set-Up Time }\end{array}$ & 3.23 & 0.731 \\
$\begin{array}{l}\text { Indicate The } \\
\text { Importance Given To } \\
\text { Throughput Time }\end{array}$ & 3.46 & 0.712 \\
$\begin{array}{l}\text { Indicate The } \\
\text { Importance Given To } \\
\text { Time To Market }\end{array}$ & 3.12 & 0.720 \\
$\begin{array}{l}\text { Indicate The } \\
\text { Importance Given To } \\
\text { Bottleneck } \\
\text { Identification }\end{array}$ & 3.01 & 0.716 \\
\hline Time Based Management & 3.29 & 0.743 \\
\hline
\end{tabular}

The lowest mean of time based management is Indicate The Importance Given To Time To Market and the average mean value of organizational capabilities is at medium levels.

\subsection{Correlation Analysis}

From the results of correlation analysis it is found that organizational capabilities are significantly correlated to manufacturing capabilities. As shown in Table 6, the correlation coefficients are found to be positive and statistically significant at 0.01 level $(p<0.01)$.

Table 6: Pearson Correlation Coefficients between Time Based Management and Manufacturing Capabilities

\begin{tabular}{lcc} 
Variable & F1 & $\begin{array}{c}\text { Correlations } \\
\text { Manufacturing Capabilities }\end{array}$ \\
\hline F1 & 1.00 & \\
Time Based Management & $0.736^{* *}$ & 1.00 \\
\hline
\end{tabular}

** Correlation is significant at the 0.01 level (1-Tailed)

* Correlation is significant at the 0.05 level (1-Tailed)

Therefore, Hypothesis 1 is supported. There is a significant relationship between time based management with the other variables that is agility (manufacturing capabilities). Hence, Hypothesis 1 is supported.

\section{Discussions}

This study is to identify empirically the core manufacturing capabilities in manufacturing industries in Malaysia. The rationale of the study stems from the major consideration, that is, the emerging concern of top management and shareholders of the manufacturing companies and the directors of the companies in this industry in particular to develop core manufacturing capabilities.

The analysis based on the respondents' perception of core manufacturing capabilities in manufacturing companies showed that manufacturers took a lot of effort in time based management in achieved high degree of core manufacturing capabilities

The findings show that time based management is the important variable that must be consider by the manufacturers in their operation. These findings are supported by previous researchers who have studied in developing manufacturing capabilities (Swink \& Hegarty, 1998; Haifeng, 2006; Li, 2000)

The correlation analysis show that time based management is the priority variables that must be highlight which show the correlations coefficients 0.736 at the 0.01 level (1-Tailed).

\section{The Limitations}

This survey has been conducted on manufacturing companies in Northern Region of Malaysia. Nevertheless, the result may not be able to generalise the 
influence of time based management on manufacturing capabilities for the whole country as there are different focus on their operation. This study focuses solely on the manufacturing capabilities in term of agility. Future research should consider other factors that influence the manufacturing capabilities quality, lean and six sigma.

\section{Conclusion}

This paper has applied empirical analysis on the influence of time based management on manufacturing capabilities of local manufacturers. Survey on manufacturing capabilities on the local manufacturers reveals that the level of manufacturing capabilities is high level. The results show that the time based management contribute to the manufacturing capabilities. The results suggest that, all manufacturers must consider time based management as their focusing aspect to survive in the business.

Companies or manufacturers must increase their time based management in term of agility to gain significantly in the core manufacturing capabilities. The time based management absolutely are very important in develops manufacturing capabilities.

\section{References}

[1] Amit, R. \& Schoemaker, P. (1993). Strategic assets and organizational rent. Strategic Management Journal; 14, (1), pp. 33-46.

[2] Barnes, D. (2001). Research Methods for the Empirical Investigation of the Process of Formation of Operations strategy. International Journal of Operations \& Production Management, 21(8), 10761095.

[3] Beach, R. Muhlemann, A.P. Price, D. Paterson, A. \& Sharp, J. (2000). Manufacturing Operations and Strategic Flexibility: Survey and Cases. International Journal of Operations \& Production Management, 20(1), 7-30

[4] Bhatt, G. \& Grover, V. (2005). Types of information technology capabilities and their role in competitive advantage: An empirical study. Journal of Management Information Systems, 22(2), 253-277.

[5] Bolden, R. Waterson, P. Warr, P. Clegg, C. \& Wall, T. (1997). A new taxonomy of modern manufacturing practices. International Journal of Operations \& Production Management, 17(11), 11121130.

[6] Coates, T. (2002). An Exploratory Analysis of New Competences: a Resource-Based View. Journal of Operations Management 20(5), 435-450.
[7] Haifeng. G. Yezhuang, T. \& Zhandong, L. (2006). An empirical analysis on relationships of manufacturing practices and manufacturing capabilities. Paper presented at the International Conference on Management of Innovation and Technology.

[8] Hair, J. Anderson, R. Tatham, R. \& Black, W. (2007). Multivariate data analysis with readings

[9] Hall, R. (1992). The strategic analysis of intangible resources. Strategic Management Journal. Vol 13. 135- 144

[10] Katz, R. Rebentisch, E. \& Allen, T. (1996) A Study of Technology Transfer in a Multinational Cooperative Joint Venture. IEEE Transactions on Engineering Management.

[11] Li, X. (2000). Manufacturing Capability development in a changing business environment. Industrial Management \& Data Systems, 100(6), 261-270.

[12] Narasimhan, T. Swink, S. \& Kim, D. (2005). An exploratory study of manufacturing practice and performance interrelationships, Implications for capability progression. International Journal of Operations \& Production Management, 25(10), 10131033.

[13] Grobler, A. (2007). A dynamic view on strategic resources and capabilities applied to an manufacturing strategy literature Journal Of Manufacturing Technology Management, 18(3).

[14] Sohal, M. Gordon, M. Fuller, T. \& Simon, K. (1999). Manufacturing practices and compatibility: An Australian study. Technovation, 19(5), $295-304$

[15] Narasimhan, T. (2005). An exploratory study of manufacturing practice and performance interrelationships, Implications for capability progression. International Journal of Operations \& Production Management, 25(10), 10131033.

[16] Swink, M. (1998). Core manufacturing capabilities and their links to product differentiation. International Journal of Operations \& Production Management, 18(4), 374- 396.

[17] Teece D. \& Shuen, A. (1997). Dynamic capabilities and strategic management. Strategic Management Journal, 18(7), 509-533.

[18] Yang, B., Burns, N.D. \& Backhouse, C.J. (2004). Postponement: A Review and Integrated Framework. International Journal of Operations \& Production Management, 24(5), 468-487.

[19] Zeleny, M. (1986). High technology management, Human Systems Management, 6(2), pp. 109-120.

[20] Zikmund, W. G. (2000). Business Research Methods. Ford Worth:The dryden Press. 